\title{
Aposentadoria espontânea e seus efeitos no contrato de trabalho
}

\author{
Kátia Alessandra Pastori Terrin ${ }^{1}$ \\ Prof. Dr. Lourival José de Oliveira ${ }^{2}$
}

\begin{abstract}
Resumo
Os efeitos da aposentadoria espontânea do empregado no contrato de trabalho desencadeiam discussões jurídicas e vêm acarretando controvérsias nos Tribunais brasileiros. A aposentadoria espontânea, conforme recente decisão do Supremo Tribunal Federal, não implica rescisão do contrato de trabalho, facultando, sim, a permanência do regular exercício das funções desempenhadas pelo empregado, sem qualquer alteração no contrato que mantém com seu empregador. Depreendese, pois, que 0 artigo 453, caput, da CLT, não se presta à disciplina dos efeitos da aposentadoria na continuidade do contrato, sendo necessária uma interpretação mais extensiva da matéria e seus efeitos, sobretudo porque a norma jurídica não pode ser considerada isoladamente, ainda mais quando existem dispositivos legais outros que norteiam o tema.
\end{abstract}

Palavras-Chave: Aposentadoria espontânea; Contrato de trabalho; Extinção.

\section{Introdução}

Tema assaz polêmico no campo do Direito do Trabalho, sobretudo ante a inexistência de tutela específica da matéria. Quando é trazida à baila a questão dos efeitos da aposentadoria espontânea do empregado no contrato de trabalho, a polêmica tem-se por instaurada, uma vez que tem sido objeto de controvérsia nos Tribunais.

Muito embora possam ser encontrados posicionamentos doutrinários e jurisprudenciais no sentido de que a aposentadoria espontânea implica rescisão do vínculo de emprego e a eventual continuação da prestação obreira representaria a firmação de um novo contrato iniciado a partir do momento da concessão da aposentadoria, ressalta-se que o Ordenamento Jurídico brasileiro em vigência nos remete à interpretação contrária.

O fato da concessão da aposentadoria espontânea não implica rescisão do contrato de trabalho, facultando, sim, a permanência do regular exercício das funções desempenhadas pelo empregado, sem qualquer alteração no contrato que mantém com seu

\footnotetext{
${ }^{1}$ Bacharel em Direito pela Universidade Estadual de Londrina.

${ }^{2}$ Doutor em Direito (PUC-SP); professor adjunto da Universidade Estadual de Londrina; professor da UNOPAR; professor da FACCAR; professor da UNIMAR.
} 
empregador. Depreende-se, pois, que o artigo 453, caput, da CLT não se presta à disciplina dos efeitos da aposentadoria na continuidade do contrato, sendo necessária uma interpretação mais extensiva da matéria, sobretudo porque a norma jurídica não pode ser considerada isoladamente, ainda mais quando existem dispositivos legais outros que tratam o tema com bem maior propriedade.

\section{Aposentadoria espontânea e o contrato de trabalho}

Os efeitos da aposentadoria espontânea do empregado no contrato de trabalho têm sido objeto de controvérsia nos Tribunais Regionais, fruto de interpretações diversas e por vezes imprecisas da sistemática legal aplicável ao fato.

Recentemente, a controvérsia sobre a questão acentuou-se em face da Lei no 9.528/97 que introduziu no artigo 453, da CLT, dois parágrafos, os quais foram suspensos em razão da concessão de liminares concedidas pelo Supremo Tribunal Federal nas Ações Diretas de Inconstitucionalidade ns. 1770-4-DF e 1721-3-DF.

Com a decisão do mérito da ADin n. 1770-4 pela Suprema Corte, cujo julgamento se deu em 11.10.06, decisão publicada em 1.12.06, foi julgado inconstitucional o parágrafo primeiro do artigo 453, da CLT, o que levantou celeuma jurídica sobre os efeitos da aposentadoria espontânea no contrato de trabalho.

A princípio, cumpre olvidar que a Constituição Federal protege o empregado contra a despedida arbitrária ou sem justa causa. Também, a extinção do contrato de trabalho em razão de aposentadoria voluntária foi introduzida na CLT sem lei complementar, em descompasso com 0 artigo 7ํ, I da Constituição Federal.

Sendo assim, o STF, ao julgar a ADIN 1.721-3, declarou inconstitucional o § 20 do artigo 453 da CLT. Na fundamentação do seu voto, que enfocava a situação do empregado particular, o M inistro Relator Carlos Brito entendeu que a aposentadoria voluntária acabaria sendo maléfica ao empregado, pois determinaria o fim instantâneo do contrato, desconsiderando a própria e eventual vontade do empregador de permanecer com seu empregado.

A primeira decisão liminar foi assim ementada: 
AÇÃO DIRETA DE INCONSTITUCIONALIDADE. ART. 3. DA MP N. 1.596-14/97 (CONVERTIDA NA LEI N. 9.528/97), NA PARTE EM QUE INCLUIU § 2. NO ART. 453 DA CLT. ALEGADA OFENSA À CONSTITUIÇÃO. 0 direito à estabilidade no emprego cedeu lugar, com a Constituição de 1988 (art. 7.․․, I), a uma proteção contra despedida arbitrária ou sem justa causa, consistente em uma indenização compensatória, entre outros direitos, a serem estipulados em lei complementar. A eficácia do dispositivo não ficou condicionada à edição da referida lei, posto haver sido estabelecida, no art. 10 do ADCT, uma multa a ser aplicada de pronto até a promulgação do referido diploma normativo (art. 10 do ADCT), havendo-se de considerar arbitrária e sem justa causa, para tal efeito, toda despedida que não se fundar em falta grave ou em motivos técnicos ou de ordem econômico-financeira, a teor do disposto nos arts. 482 e 165 da CLT. 0 diploma normativo impugnado, todavia, ao dispor que a aposentadoria concedida a empregado que não tiver completado 35 anos de serviço (aposentadoria proporcional por tempo de serviço) importa extinção do vínculo empregatício - efeito que o instituto até então não produzia -, na verdade, outra coisa não fez senão criar modalidade de despedida arbitrária ou sem justa causa, sem indenização, o que não poderia ter feito sem ofensa ao dispositivo constitucional sob enfoque. Presença dos requisitos de relevância do fundamento do pedido e da conveniência de pronta suspensão da eficácia do dispositivo impugnado. Cautelar deferida (STF - ADIn 1721-3, Relator M inistro Ilmar Galvão, DJU de 11/04/2003).

Observa-se que foi utilizado como argumento para o deferimento da liminar o fato de que a Constituição Federal considera devida a indenização do inciso I do artigo 7. (40\% do FGTS) na despedida arbitrária ou sem justa causa. Elucida ainda o Ministro Relator que o disposto no parágrafo 2ำ do artigo 453 da CLT, criou nova modalidade de despedida arbitrária ou sem justa (a aposentadoria espontânea como razão da extinção do contrato de trabalho), sem indenização, o que não poderia ter feito sem ofensa ao disposto no aludido inciso I do artigo 7.ำ da Norma Maior, que assegura a aludida indenização ao trabalhador.

Já no que tange a ADIn 1.770, a ementa da liminar teve o seguinte teor:

AÇÃO DIRETA DE INCONSTITUCIONALIDADE. § 1. DO ARTIGO 453 DA CLT NA REDAÇÃO DADA PELO ARTIGO 3. DA LEI 9.528, DE 10.12.97, E DO ARTIGO 11, "CAPUT" E PARÁGRAFOS, DA REFERIDA LEI. PEDIDO DE LIMIAR. No tocante ao artigo 11 da Lei 9.528/97, não é de conhecer-se a ação direta, porquanto, tratando de norma temporária cujos prazos nela fixados já se exauriram no curso deste processo, perdeu a referida ação o seu objeto. Quanto ao § 1.ำ do artigo 453 da CLT na redação dada pelo artigo 3.ㅇ da Lei 9.528/97, ocorre a relevância da fundamentação jurídica da argüição de inconstitucionalidade, bem como a conveniência da suspensão de sua eficácia pelas repercussões sociais decorrentes desse dispositivo legal. Pedido de liminar que se defere, para suspender, "ex nunc" e até decisão final, a eficácia do $\S 1$. do artigo 453 da CLT na redação que Ihe deu 0 artigo 3.- da Lei 9.528, de 10 de dezembro de 1997 (STF -ADIn 1770 - 4, Relator Ministro Moreira Alves, DJU de 06/11/1998). 
Outrossim, na ADIN 1.770-4, o STF ao declarar a inconstitucionalidade do $\S 10$ do artigo 453 da CLT, visualiza-se o fundamento de que a inconstitucionalidade do dispositivo legal em causa decorre do fato de que o mesmo pressupõe indiretamente que a aposentadoria espontânea do empregado extingue automaticamente 0 vínculo empregatício, o que viola os preceitos constitucionais relativos à proteção do trabalho e à garantia de percepção dos benefícios previdenciários, que por si só foi suficiente para se considerar relevante a necessidade de suspensão do dispositivo celetista diante dos prejuízos para os trabalhadores e das repercussões sociais decorrentes em tais situações.

Assim sendo, os $\S \S 10$ e $2^{\circ}$ do artigo 453 da CLT foram declarados inconstitucionais pelo Supremo Tribunal Federal, nas ADINS 1770-4 e 1721-3 (julgamento de 11.10.06), respectivamente, gerando conseqüências de ordem jurídica e prática.

Bom registrar ainda que as decisões em comento, exaradas em sede de controle concentrado de constitucionalidade, são imantadas de efeitos contra todos (erga omnes), com caráter retroativo (ex tunc) e vinculante.

Não sem razão que, tão-logo publicada a decisão da Suprema Corte, tratou imediatamente o TST de cancelar a OJ 177 de sua SDI-1, que outrora fixava: "A aposentadoria espontânea extingue 0 contrato de trabalho, mesmo quando o empregado continua a trabalhar na empresa após a concessão do benefício previdenciário. Assim sendo, indevida a multa de $40 \%$ do FGTS em relação ao período anterior à aposentadoria". Haja vista que tal sinalização jurisprudencial, por óbvio, revelava conteúdo oposto à conclusão enunciada pelo STF. (FERNANDES JUNIOR, 2006, p. 130)

Contudo, há que se observar que o cancelamento da Orientação Jurisprudencial no 177 da Seção de Dissídios Individuais do TST, noticiada em 26/10/2006 por intermédio do M inistro Vantuil Abdala, presidente da Comissão de Jurisprudências, não significa por si só uma tomada de posição quanto ao mérito do assunto, mas sim uma maneira para que a jurisprudências evoluam naturalmente de acordo com as convicções de cada ministro, e que por conseqüência, uma nova jurisprudência surja com relação ao assunto.

Ressalta-se também que alguns entendem que as ADIns ns. 1721-3 e 1770-4 foram ajuizadas em face da Lei n. 9.528/97 que acrescentou os dois parágrafos no art. 453, da CLT e sobre os dois dispositivos é que se deu a apreciação do Supremo Tribunal Federal, restando incólume a redação do caput do art. 453, da CLT, que somente poderia ser 
afastada da ordem jurídica se fosse declarada inconstitucional com pedido expresso nesse sentido. (M ARTINS, 2007, p. 17)

No entanto, é importante pontuar que o ponto nevrálgico aqui não é o texto da lei isoladamente considerado, mas sim o contexto do direito, considerado como um sistema que, no caso, teve retirado de seu bojo a regra que via na aposentadoria espontânea um fator de encerramento do enlace empregatício.

A interpretação desse dispositivo - CLT, artigo 453, caput -, agora, no tocante a essa temática, volta-se estritamente para as "cada vez mais raras hipóteses em que a aposentadoria é acompanhada do pedido de demissão ou dispensa (normalmente sem justa causa) pelo empregador, e o empregado, em seguida ou posteriormente, é readmitido, ou seja, contratado novamente". (BARBOSA GARCIA, 2007, p. 22)

Sendo assim, não se pode extrair do caput do artigo 453 da CLT a tese de que a aposentadoria espontânea encerra ope legis o contrato de trabalho (motivação externa oriunda da lei), eis que tal ilação fora expressamente repelida do ordenamento jurídico pátrio, à vista das decisões lançadas pelo STF nas ADI's n. 1.721 e n. 1.770.

Nesse quadro, para que o evento aposentadoria seja seguido do evento extinção do pacto laboral, urge, pois, que qualquer das partes da relação trabalhista assim se manifeste, atentando, sempre, óbvio, para os efeitos jurídicos decorrentes da modalidade de extinção perpetrada (rescisão, resilição ou resolução contratuais). (GODINHO, 2006, p. 1.121)

Destaca-se ainda o entendimento de que a aposentadoria por tempo de serviço não extingue 0 contrato de trabalho, uma porque os seus efeitos estão adstritos à relação jurídica de natureza previdenciária que o trabalhador mantém com a Previdência Social; e duas porque a extinção automática do contrato de trabalho implicaria vilipêndio ao artigo 70, inciso I, da CF, que veda a dispensa arbitrária e sem justa causa (CARM 0, 2006, p. 956).

Ressalta-se que não existe hoje nenhum dispositivo de natureza previdenciária dispondo que a aposentadoria por tempo de serviço implica automaticamente a extinção do contrato de trabalho, haja vista que o benefício previdenciário em questão pode ser requerido pelo trabalhador, mesmo quando não se afasta do emprego.

Não obstante doutrinas e jurisprudências se manifestarem no sentido de que a aposentadoria espontânea implica rescisão do contrato de trabalho e a eventual continuação da prestação obreira representaria a firmação de um novo contrato, iniciado a 
partir do momento da concessão da aposentadoria, há que se observar que nosso ordenamento jurídico em vigência nos remete à interpretação contrária, revelando que o simples fato da concessão da aposentadoria espontânea não implica rescisão do contrato de trabalho, facultando, sim, a permanência do regular exercício das funções desempenhadas pelo empregado, sem qualquer alteração no contrato que mantém com seu empregador.

Para uma melhor compreensão sobre o tema, é válido iniciar a abordagem com uma breve evolução legislativa do artigo 453, da CLT e da Lei n. 4.090/62, no que tange a aposentadoria e cessação do contrato de trabalho.

Na redação original do artigo 453 da CLT, que decorreu do Decreto n. 5.452/43, não constava a aposentadoria como causa da cessação do contrato de trabalho e que assim dispunha:

No tempo de serviço de empregado, quando readmitido, serão computados os períodos, ainda que não contínuos, em que tiver trabalhando anteriormente na empresa, salvo se houver sido despedido por falta grave ou tiver recebido indenização legal.

Entretanto, com a Lei n. 6.204/75, mencionado artigo passou a vigorar com 0 acréscimo ao final da expressão "ou se aposentado espontaneamente".

Tão evidente ficou para o legislador ordinário que a aposentadoria era causa de extinção do contrato de trabalho que foi acrescentado pela Lei n. 9.011, de 30.3.95, 0 item II no parágrafo 3ำ da Lei n. 4.090/62, a qual trata da gratificação de natal, para estabelecer que a gratificação será proporcional "na cessação da relação de emprego resultante da aposentadoria do trabalhador, ainda que verificada antes de dezembro".

Finalmente a Lei n. 9.528/97 introduziu os parágrafos primeiro e segundo no artigo 453, com a seguinte redação:

Art. 453[...]

$\S 1$ - Na aposentadoria espontânea de empregados das empresas públicas e sociedades de economia mista é permitida sua readmissão desde que atendidos os requisitos constantes do art. $37, \mathrm{XVI}$, da Constituição Federal, e condicionada à prestação de concurso público.

$\S 2-0$ ato de concessão de benefício de aposentadoria a empregado que não tiver completado 35 (trinta e cinco) anos de serviço, se homem, ou 30 (trinta), se mulher, importa em extinção do vínculo empregatício. 
Logo, caberá ao operador do direito, a partir de agora, extrair suas conclusões jurídicas a respeito do tema diante das recentes decisões do STF em matéria constitucional.

\section{Breves considerações acerca da aposentadoria e a extinção do contrato de trabalho.}

No direito comparado são encontradas legislações que consagram a cessação do contrato de trabalho pela aposentadoria do empregado, embora algumas delas não mencionem a possibilidade de o empregado continuar a trabalhar na empresa.

Sinalizam, portanto, que na maioria dos países a aposentadoria é causa extintiva do contrato de trabalho, sendo que alguns países estabelecem mecanismos que estimulem a aposentadoria.

$\mathrm{Na}$ Espanha, o Estatuto dos Trabalhadores dispõe que o contrato de trabalho se extinguirá com a aposentadoria do trabalhador. Em Portugal, a cessação automática do contrato de trabalho se dá como forma de libertar efetivamente postos de trabalho a partir de certo momento, preocupação esta surgida com uma grave crise de desemprego. (M ONTEIRO apud M ARTINS, 2007).

$\mathrm{Na}$ Argentina, quando o trabalhador possa requerer o benefício previdenciário pelo percentual máximo, o empregador é obrigado a manter o empregado pelo tempo máximo de um ano. Concedido o benefício ou vencido o prazo mencionado o contrato de trabalho fica extinto.

A extinção do contrato em decorrência da aposentadoria também é verificada na Grã Bretanha, França, Bélgica, Alemanha e Itália. Porém, sabe-se que no Brasil a realidade é outra.

O benefício previdenciário que a princípio deveria ser tido como um prêmio àquele que trabalhou e contribuiu à Previdência Social durante sua vida, para que finalmente pudesse descansar e desfrutar de sua aposentadoria tornou-se um complemento econômico fundamental diante da dura realidade financeira em que vive o povo brasileiro.

A realidade social brasileira, marcada pela divisão de classes e crescente desigualdade econômica entre os cidadãos exige que muitos trabalhadores permaneçam em seus empregos, mesmos após se encontrarem aparados pelo benefício constitucional e previdenciário da aposentadoria, como forma de garantir seu sustento e de sua família. 
Motivo pelo qual, quando se analisa a questão da aposentadoria espontânea e seus efeitos no contrato de trabalho do brasileiro, deve-se levar em conta essa realidade, destacando que a discussão não é tão simples quanto possa parecer.

No entanto, há que se observar ainda uma nova realidade trazida à baila com a recente decisão do Supremo Tribunal Federal acerca da aposentadoria espontânea não mais como causa de extinção do contrato de trabalho.

Ou seja, as empresas, figurando como empregadoras, continuarão mantendo em seu quadro de empregados os aposentados, tendo em vista a possível conseqüência que surge, qual seja, a multa fundiária sobre todo o perío do laborado?

A resposta não se apresenta de forma simples.

Cumpre destacar o evidente ônus imposto ao empregador, resultante da soma dos períodos descontínuos de trabalho, fator este que pode ser altamente negativo ao reaproveitamento de empregados aposentados, porém aptos para o trabalho.

Contudo, não há que se negar que na realidade brasileira, a carência de mão-deobra qualificada urge constantemente. Tampouco se nega que a necessidade dessa mão-deobra, para o Governo, possa levá-lo a bom termo seu próprio desenvolvimento econômico e social.

Parece claro, no entanto, que facilitar o reaproveitamento de todo empregado qualificado ainda apto para trabalhar, embora já aposentado, atende não apenas aos interesses do próprio empregado, possibilitando-Ihe elevação de sua renda, mas também da própria economia do país, com fortalecimento, inclusive do mercado interno.

Tendo em vista ainda o alto custo na formação de empregados qualificados, e a despeito dos esforços realizados pelo Governo para ampliar e facilitar essa formação, M elchíades Rodrigues M artins observa que "não pode o Brasil se dar ao luxo de marginalizar empregados qualificados". (MARTINS, 2007, p. 21)

Assim sendo, é necessário que se tenha a exata dimensão do conflito de interesses e suas repercussões nas esferas jurídicas, buscando sempre compatibilizá-los, posto que há dois interesses jurídicos dos mais relevantes que não se contrapõe, mas, ao contrário, podem e devem coexistir. 


\section{0 término do contrato de trabalho}

0 momento final da relação de emprego é a desconstituição do vínculo. Nesse sentido, terminação e cessação são expressões idênticas e que indicam a referida desconstituição do vínculo de emprego. Ambas indicam o gênero da qual são espécies a dissolução, extinção, rescisão, resilição e resolução que não teve o legislador celetário maior preocupação em distingui-las. (HALPERN, 2007, p. 726).

Já a cessação do contrato de trabalho é a terminação do vínculo de emprego, com a extinção das obrigações para os contratantes na visão doutrinária. 0 professor Amauri M ascaro Nascimento utiliza a expressão "extinção do contrato de trabalho" para designar o fim das relações jurídicas em geral. (NASCIM ENTO, 2001, p. 551).

A Consolidação das Leis do Trabalho utiliza a expressão rescisão para qualquer hipótese de extinção contratual, independentemente dos clássicos conceitos do Direito Civil ao tratar da rescisão, resilição e resolução contratual.

Ocorre que, conforme dito, recentemente surgiu muita controvérsia sobre a questão em face da Lei n. 9.528/97 que introduziu no art. 453 da CLT, dois parágrafos, os quais foram suspensos em razão da concessão de liminares pelo Supremo Tribunal Federal nas ADIns ns. 1770-4-DF e 1721-3-DF, e posteriormente julgados inconstitucionais.

Depreende-se, no entanto, que o artigo 453 - caput -, da CLT, não se presta à disciplina dos efeitos da aposentadoria na continuidade do contrato, sendo necessária uma interpretação mais extensiva da matéria, para o que se deve socorrer de outros elementos do Ordenamento Jurídico ora vigente, sobretudo porque a norma jurídica não pode ser considerada isoladamente, ainda mais quando existem dispositivos legais outros que tratam o tema com bem maior propriedade.

Dentre esses elementos, de suma importância o teor da atual lei de Previdência Social - Lei 8.213, de 1991, que, em seu artigo 49, reza:

A aposentadoria por idade será devida: I.- ao segurado empregado, inclusive doméstico, a partir: a) da data do desligamento do emprego, quando requerida até esta data ou até 90 dias depois dela; ou b) da data do requerimento, quando não houver desligamento do emprego ou quando for requerida após o prazo previsto na alínea "a". 
Não bastasse isso, a própria CLT, quando pretendeu determinar as oportunidades em que a aposentadoria implica rescisão do contrato de trabalho, assim o fez de modo expresso, através do parágrafo segundo, introduzido no próprio o artigo 453, no qual se lê: "Art. 453: [...] $§ 20$ - 0 ato de concessão de benefício de aposentadoria a empregado que não tiver completado 35 (trinta e cinco) anos de serviço, se homem, ou 30 (trinta), se mulher, importa em extinção do vínculo empregatício".

Ora, se a matéria foi expressamente regulada para determinar a hipótese em que 0 vínculo de emprego se desfaz com a aposentadoria, não se há como depreender que a cessação do contrato seja a regra geral, pois, se assim o fosse, despicienda se faria a tutela de hipóteses específicas, como consignado do parágrafo acima. E, se não é a regra, por óbvio, há de ser considerada exceção, reforçando ainda mais o entendimento nesta oportunidade defendido.

A rescisão do contrato de trabalho, à luz dos dispositivos legais hoje vigentes, não decorre automaticamente da aposentadoria espontânea, subsistindo, sim, a faculdade de 0 empregado persistir na prestação de seus serviços, sem prejuízo do contrato de trabalho e de todos os efeitos dele decorrentes.

Ademais, desde 0 advento da Lei no 8.213/91, a aposentadoria voluntária passou a ser um direito social do empregado sem que acarrete a resilição contratual do obreiro para com o empregador, conforme disposto no art. 49, inciso I, letra "b" da Lei $n=8.213$ de 24 de julho de 1991.

A Lei n. 9.032 de 28 de abril de 1995, ao alterar as Leis 8.212 e 8.213, ambas de 1991, referendou a possibilidade de o empregado continuar trabalhando ao requerer a aposentadoria, ao dispor expressamente no artigo 20 que 0 aposentado que continuasse em suas atividades, ou que, voltasse a exercê-las após a aposentadoria espontânea, seria considerado como segurado obrigatório, passando a ter contribuição compulsória.

Portanto, a aposentadoria espontânea, per si, não é causa de extinção do contrato de trabalho, sendo necessária manifestação livre e expressa da vontade do empregado em continuar ou não com o seu vínculo empregatício com o empregador, cuja manifestação há de ser expressa.

Verifica-se, daí, que o ordenamento jurídico pátrio, desde o advento da Lei oㅡ 8.213/91 não exige a extinção do contrato de trabalho para concessão da aposentadoria. Por 
conseqüência, o empregado que, requerendo aposentadoria voluntária, continuasse a trabalhar, continuaria com seu contrato de trabalho em vigor, mantendo todos os seus direitos.

Frisa-se que 0 mero interesse do empregado em requerer 0 benefício previdenciário da aposentadoria, por si só, não caracteriza a anuência dele em romper o vínculo empregatício com o empregador, sendo necessária livre manifestação de vontade deste em afastar-se do trabalho.

Nesse sentido, é o entendimento de Wladimir Novaes Martinez, quando escreve que subsiste o direito de laborar, de manter o contrato de trabalho e anterior vantagem, desde que não seja por invalidez. Sendo assim, o pedido de benefício não promove a rescisão contratual, esta sim, deriva da vontade do obreiro deixar de prestar serviço.

E não sendo condição legal, como era na Consolidação das Leis da Previdência Social, para o exercício do direito, se a empresa não deseja mais o aposentado prestando-lhe serviço, deve rescindir-lhe o contrato, assumindo, conseqüentemente as obrigações advindas e previstas em lei. (M ARTINEZ, 1992, p. 184).

No mesmo sentido se manifesta José Martins Catharino $(2006$, p. 78 ) em sua obra Direito do Trabalho:

Em se tratando de aposentadoria por velhice e por tempo de serviço, o fato voluntário é essencial (não há, no Direito do Trabalho, aposentadoria compulsória e automática, como a do funcionário público . Constituição Federal, 101, II). Não havendo, é insustentável, sem norma expressa, dizer-se que as mesmas aposentadorias acarretam, necessariamente, a terminação do contrato de emprego. Portanto, deixará de haver demissão indireta ou mediata, ou oblíqua, com as aposentadorias em causa, como no Direito anterior.

Para arrematar esse entendimento, merece transcrição parte do exímio parecer elaborado por Arion Sayão Romita (2007, p. 1051), publicado na LTr 60-08:

Segundo o direito positivo brasileiro vigente, a aposentadoria voluntária do empregado não extingue 0 contrato de trabalho. Nenhum dispositivo legal regula 0 efeito erradicado pela aposentadoria sobre o contrato de trabalho. 0 instituto da aposentadoria não traz em si, implícito, o efeito da extinção do vínculo, a menos que o empregado opte pelo afastamento da atividade. Como a lei previdenciária permite, expressamente, a permanência do segurado na atividade, segue-se que a aposentadoria não constitui causa de extinção automática do vínculo empregatício. Se o empregado permanece na empresa, o contrato de trabalho prossegue em sua vigência normal. A relação previdenciária, entre o segurado e a autarquia INSS, não 
interfere na relação empregatícia (entre 0 trabalhador e respectivo empregador). Os direitos que o empregado adquire em face do empregador não são afetados pelo fato de ter ele obtido um benefício previdenciário, o que se credenciaria perante 0 INSS.

Duas são, portanto, as possíveis conseqüências jurídicas da obtenção, pelo empregado, da aposentadoria previdenciária: quando o empregado se aposenta pelo INSS e se afasta da atividade; ou quando o empregado obtém o benefício previdenciário, mas prefere continuar em atividade (aposentado ativo).

Há que se observar que na primeira hipótese, não há dúvida de que a aposentadoria extingue o contrato de trabalho, com todas as conseqüências jurídicas daí decorrentes. Contudo, na segunda hipótese, inocorre a extinção do contrato de trabalho, porque a lei previdenciária não exige mais o desligamento para a concessão do benefício. 0 direito de trabalhar não se confunde com o direito aos benefícios previdenciários, podendo um mesmo sujeito exercê-los simultaneamente.

Como se sabe, a vontade é um dos elementos que informam a existência do negócio jurídico, sendo que, a sua manifestação livre, assume a condição de pressuposto de validade.

Diz-se, assim, que a vontade manifestada corretamente tem o condão de produzir o nascimento, a modificação ou a extinção da relação jurídica válida. A palavra "corretamente" deve ser entendida no sentido de juridicamente eficaz, apta a produzir efeitos no mundo do direito, o que não ocorreu no requerimento de aposentadoria do reclamante.

Portanto, baseado no art. 49, da lei $8213 / 9$ e na decisão proferida pelo Supremo Tribunal Federal nas ADI 1721 e 1770, têm-se por evidenciado que a aposentadoria espontânea, por si só, não é causa extintiva do contrato de trabalho, e que a imposição da aceitação de tal condição pelo empregador no momento da aposentadoria do empregado é ilegal, tornando o consentimento viciado, uma vez que o disposto no artigo 7ํ. I, da CF, protege a relação de emprego contra despedida arbitrária e sem justa causa.

\section{Efeitos da aposentadoria no contrato de trabalho (continuidade do vínculo e FGTS).}

Quando por convergência de vontades entre empregador e trabalhador há a continuidade do vínculo empregatício, após o evento aposentadoria, a conseqüência jurídica 
imediata que daí decorre é a unicidade da relação jurídica laboral, tendo o empregado direito às verbas trabalhistas integrais, se, e quando houver superveniente ruptura do contrato de trabalho sem justa causa.

Situação diferente acontece quando 0 empregador, ciente da aposentadoria requerida pelo empregado e no seu próprio interesse, faz cessar de imediato o relacionamento empregatício, não se interessando pela sua permanência em serviço.

Quando, na singularidade do caso concreto, não há prestação de trabalho após o evento aposentadoria, ou mesmo quando o trabalhador só permanece no emprego o tempo necessário ao processamento previdenciário de seu pedido de aposentadoria, o motivo da ruptura contratual é o próprio evento da jubilação, o qual norteará lógica e inexoravelmente quais serão os direitos trabalhistas conquistados pelo trabalhador.

Nesta hipótese há previsão legal de levantamento do FGTS sem o adicional de 40\% e a desnecessidade de pagamento de aviso prévio por parte do empregador, subsistindo as demais obrigações reparatórias calcadas na rescisão contratual sem culpa do empresário.

Observa-se, no entanto, que as Turmas do TST vêm adotando diferentes posicionamentos. A Quarta Turma, em julgamento (RR 616084/1999) decidiu com base na Lei n. 5.107/66 (que instituiu o FGTS) que, ainda que o contrato seja único, a multa de $40 \%$ só incide sobre os depósitos efetuados após a aposentadoria. A Primeira, Segunda, Terceira e Quinta Turmas, em situações semelhantes, julgaram no sentido de que a multa deve ser calculada com base no total dos depósitos do FGTS. (M ARTINS, 2007, p. 21)

Essas diferentes interpretações, gradualmente irão chegar à seção Especializada em Dissídios Individuais I, na forma de embargos em recurso de revista (recurso contra decisões de Turmas com decisões divergentes entre elas). Caberá, portanto, à SDI-I, conforme suas atribuições definidas no Regimento Interno do TST, julgar esses embargos.

Contudo, a verdade é que a SDI-I já julgou um outro caso, e, se posicionou (com votos divergentes) no sentido de que a aposentadoria não rescinde o contrato de trabalho (RR-666.618/2000).

Observa-se ainda que há que se levar em conta que o artigo 453 da CLT que trata do tempo de serviço do empregado readmitido e que recebeu acréscimo da Lei oㅡ 6.204/75, deve ser interpretado levando-se em consideração o momento histórico no qual a lei foi editada. À época, havia divergência doutrinária e jurisprudencial sobre se, havendo 
readmissão, o empregado tinha ou não direito a computar em seu tempo de serviço o período que antecedeu a aposentadoria. Contudo, a questão perdeu atualidade por força da Constituição de 1988, que suprimiu a indenização por tempo de serviço e a estabilidade.

Quando o artigo 453 da CLT foi alterado, na vigência da Lei no 6.950/81(que fixou novo limite máximo do salário-de-contribuição), o desligamento do empregado era condição sine qua non para a obtenção da aposentadoria. Já sob a vigência da Lei no 8.213/91 (que dispôs sobre Planos de Benefícios da Previdência Social), a aposentadoria não constitui causa para o fim do vínculo contratual.

Diante disso, como não ocorre a rescisão do contrato de trabalho por força da aposentadoria, o empregado conserva o direito de receber a multa de $40 \%$ sobre todos os depósitos do FGTS, abrangendo os efetivados antes e depois da aposentadoria.

Outrossim, somente quando o empregador, tácita ou expressamente, anui com a prorrogação do contrato de trabalho após o evento aposentadoria espontânea é que surge o espaço jurídico para a discussão da unicidade contratual do vínculo empregatício e o posterior pagamento de verbas rescisórias integrais em caso de eventual ruptura do contrato de trabalho por denúncia vazia perpetrada pelo empregador. (CARM0, 2006, p. 957)

Resta saber, diante da atual situação, se os aposentados voluntariamente continuarão ou não trabalhando na mesma empresa, por conta que o empregador poderá encarar esta nova situação como um risco empresarial de, dando continuidade ao vínculo, ter futuramente que pagar ao empregado, na hipótese de demissão sem justa causa, uma razoável soma por conta da multa sobre o valor do FGTS, que incidirá levando-se em consideração todo o período trabalhado na empresa.

Sendo assim, têm-se duas questões. A primeira, onde efetivamente foi dada interpretação em consonância com o texto da Constituição Federal, que definitivamente protege o empregado contra demissão desmotivada, e, a outra, em se saber se empregados aposentados irão conseguir efetivamente continuar trabalhando na mesma empresa que por décadas laborou. Não deve ser esquecido que nenhum outro lugar o aposentado será mais bem recebido que na empresa onde trabalhava. Diante dos pequenos valores pagos pela previdência social e tendo ele necessidade de continuar trabalhando, esta justa decisão 
poderá contribuir para a sua não permanência na empresa onde trabalhava, após a sua aposentadoria.

\section{Conclusão}

Corriqueira em nosso país é a continuidade da atividade laboral posteriormente à aposentadoria, em decorrência da necessidade econômica do hipossuficiente. As pré-citadas decisões do STF confirmam esta realidade, considerando que a aposentadoria não interfere no contrato de trabalho, que permanece integro até que o empregado decida afastar-se espontaneamente de sua atividade, ou ainda, na hipótese de resilição pelo empregador, com o pagamento das verbas rescisórias correspondentes à integralidade do período trabalhado, contando-se o tempo anterior à aposentadoria. Neste caso o empregador deve arcar com o pagamento das verbas rescisórias, inclusive a multa fundiária sobre o saldo da conta vinculada do FGTS referente ao período de prestação de serviços, inclusive anterior à aposentadoria.

O juiz ao aplicar a lei deve atender aos fins sociais a qual se dirige e às exigências do bem comum. Sendo assim, considerando que a aposentadoria espontânea, na realidade brasileira, não raras vezes não proporciona condições para que o trabalhador passe para a inatividade de forma estável financeiramente, precisando continuar trabalhando para prover seu sustento, pode ocorrer de as empresas não se sentirem mais favorecidas com a continuidade do aposentado na sua labuta normal.

Não se pode conceber, portanto, que o entendimento da extinção da relação de emprego pela aposentadoria espontânea, quando inexiste a cessação da relação de trabalho pelo empregado, seja a regra, uma vez que não há ordem legal expressa a respeito. Agiu corretamente a Corte Suprema ao decidir pela não extinção do contrato de trabalho, ante a aposentadoria espontânea. Porém, não se sabe ainda ao certo quais serão os reflexos sociais dessa decisão.

\section{Referências}

BARBOSA GARCIA, Gustavo Filipe. Aposentadoria e Contrato de Trabalho: Atualidades e Reflexos decorrentes da Jurisprudência do STF. RDT, v. 13, n. 01, p. 19-22, jan. 2007. 
REBELO, Fabricio. Aposentadoria espontânea $x$ contrato de trabalho. 0 mito da rescisão. Jus Navigandi, Teresina, v. 5, n. 49, fev. 2001.

CARM 0, Julio Bernado do. Aposentadoria espontânea e contrato de trabalho. Revista LTr. 70-08, v. 70, n. 08, p. 957, ago. 2006.

CATHARINO, José M artins. Direito do trabalho. 1. ed. São Paulo: LTr, 2007.

DELGADO, Maurício Godinho. Curso de direito do trabalho. 3. ed. São Paulo : LTr, 2007.

FERNANDES JUNIOR, Raimundo Itamar Lemos. A Inconstitucionalidade da Regra. Revista do Programa de Pós-Graduação em Direito da Universidade da Amazônia - UNAM A. v. 1, n. 2, p. 123-130, nov. 2006.

FERRARI, Irany. A aposentadoria espontânea do empregado é causa de rescisão de seu contrato de trabalho? Revista LTr. 71-07, v. 71, n. 07, jul.2007.

HALPERN, Jairo. FGTS, Multa de 40\% e cancelamento da 0J n. 177 da SDI-1 do TST - Uma abordagem cotidiana do Direito do trabalho e das relações sociais e institucionais - Uma breve visão opinativa. Revista LTr. 71-07. Vol. 71, n. 06, Junho de 2007. P. 726.

M ARTINS, M elchíades Rodrigues. Aposentadoria e extinção do contrato de trabalho. Revista LTr. 71-01. Vol. 71, n. 01, Janeiro de 2007. p. 21.

M ARTINEZ, Wladimir Novaes. Comentários à Lei Básica da Previdência Social. Vol. II, Editora LTr, S. Paulo, 1992. p. 184.

M ORAES, Alexande de. Direito Constitucional. 13a ed. São Paulo: Atlas, 2003.

NASCIM ENTO, Amauri M ascaro. Curso de Direito do Trabalho. 17 ed. São Paulo: Saraiva, 2001.

ROM ITA, Arion Sayão. Revista LTr. Vol 60-08. Junho de 2007. p. 1051 